\title{
Titanium oxide - reduced graphene oxide - silver composite layers synthesized by laser technique: Wetting and electrical properties
}

E. György, ${ }^{1,2}$ A. Perez del Pino, ${ }^{2}$ A. Datcu, ${ }^{1}$ L. Duta, ${ }^{1}$ C. Logofatu, ${ }^{3}$ I. Iordache, ${ }^{1}$ A. Duta ${ }^{4}$

${ }^{1}$ National Institute for Lasers, Plasma and Radiation Physics, P. O. Box MG 36, 77125 Bucharest, Romania

${ }^{2}$ Consejo Superior de Investigaciones Científicas, Instituto de Ciencia de Materiales de Barcelona (CSIC-ICMAB), Campus UAB, 08193 Bellaterra, Spain

${ }^{3}$ National Institute for Materials Physics, P. O. Box MG. 7, 77125 Bucharest, Romania

${ }^{4}$ Product Design for Sustainable Development, Transilvania University of Brasov, Eroilor 29, 500036, Brasov, Romania

\begin{abstract}
Titanium dioxide $\left(\mathrm{TiO}_{2}\right), \mathrm{TiO}_{2} /$ silver (Ag), and ternary $\mathrm{TiO}_{2} /$ grapheme oxide (GO) / Ag nanocomposite coatings were synthesized by matrix assisted pulsed laser evaporation, a laser-based environmental friendly thin film deposition technique. $\mathrm{TiO}_{2}$ and $\mathrm{Ag} \mathrm{NPs}$, as well as $\mathrm{GO}$ platelets were used as base materials for the preparation of the composite target dispersions. An UV KrF* excimer laser $\left(\lambda=248 \mathrm{~nm}, \tau_{\mathrm{FWHM}} \sim 25 \mathrm{~ns}, v=10 \mathrm{~Hz}\right)$ was used for the irradiation of the composite targets. The experiments were performed in controlled oxygen atmosphere. The functional, wetting and electrical properties of the layers were investigated as a function of target composition as well as ambient oxygen pressure value. The coatings exhibited hydrophobic character. The lowest electrical resistance value was measured for the ternary $\mathrm{TiO}_{2} / \mathrm{GO} / \mathrm{Ag}$ coatings with the high Ag NPs loading, deposited at low ambient oxygen pressure.
\end{abstract}

Keywords: titanium oxide / graphene oxide / silver nanocomposite layers; multifunctional properties; hydrophobic; conductive; laser processing and immobilization;

*Corresponding author, e-mail egyorgy@icmab.es, tel. +34 935801853 (ext. 369), fax. +34 935805729 


\section{Introduccion}

Titanium oxide $\left(\mathrm{TiO}_{2}\right)$ is an extensively investigated semiconductor material owing to its outsanding properties such as nontoxicity, earth abundance, low cost, chemical and biological inertness, thermal stability [1, 2]. Due to its high photoactivity, $\mathrm{TiO}_{2}$ shows great potential for environmental applications such as solar energy conversion and storage and photocatalytic dissociation of organic compounds for waste-water treatment, disinfection, as well as air purification [3-5]. Moreover, $\mathrm{TiO}_{2}$ surfaces are hydrophobic. On hydrophobic surfaces the water droplets flow freely and contaminants are carried along, being washed away. Coating of materials surfaces with highly hydrophobic water-repellent layers confer to them valuable self-cleaning properties, required for many application fields as for example windows, microfluidics, photovoltaic, biomedical devices, anti-bacterial surfaces and textiles.

Self-cleaning property was found to be a collective effect between the wetting characteristics of the materials and photocatalytic reactions. Indeed, organic contaminants can be removed from $\mathrm{TiO}_{2}$ surfaces by UV light induced photocatalytic reactions [6]. When $\mathrm{TiO}_{2}$ is irradiated with a photon energy higher or equal to its bandgap, electron-hole pairs are generated. However, the photocatalytic activity of $\mathrm{TiO}_{2}$ is constrained by the fast recombination of the generated charge carriers [7]. Noble metal nanoparticles (NPs), Ag, Au, Pt, or Pd can act as scavengers for the photoinduced electrons improving this way the photocatalytic activity of $\mathrm{TiO}_{2}$ [7, 8]. Addition of conducting carbon nanomaterials as carbon nanotubes [9] or reduced GO (rGO) [10] is another approach to reduce recombination rate of charge carriers and to promote electron transport. According to our recent investigations [11] the photocatalytic activity of the $\mathrm{TiO}_{2} / \mathrm{rGO} / \mathrm{Au}$ ternary nanocomposite materials is around $170 \%$ higher than that of pure $\mathrm{TiO}_{2}$.

Carbon nanomaterials add also additional functionalities for the hydrophilic surface. It is known, that surface electroconductivity is also important in environmental self-cleaning applications [12 14]. Previous investigations demonstrate that highly conductive surfaces avoid adsorption of organic contaminants by antistatic effect $[13,14]$. Moreover, multifunctional electrically conductive and highly hydrophobic surfaces have many attractive applications such as electrical circuits protecting them from short-circuiting and corrosion in water, electromagnetic shielding, or static charge dissipation, micro-fluidics, electrodes for fuel cells, solar panels, non-fouling surfaces. [15]. 
In the present work, we report the deposition by matrix assisted pulsed laser evaporation (MAPLE) technique of $\mathrm{TiO}_{2} / \mathrm{GO} / \mathrm{Ag}$ ternary nanocomposite thin films. The main advantage of MAPLE is that complex multicomponent materials can be synthesised and deposited on practically any type of substrate materials, including flexible organics, in a single technological step. Laser deposition methods have also other advantages over conventional techniques. The chemical composition and quantity of the transferred material can be controlled through the irradiation process parameters as laser pulse energy, number of subsequent laser pulses applied for the irradiation of the targets, as well as nature and pressure of the ambient gas in the irradiation chamber [16, 17]. Moreover, laser deposition methods are characterized by reduced processing time, high reproducibility, and very low risk of cross-contamination due to the use of light as energy source.

In this work we establish a correlation between processing parameters, surface morphology and chemical composition, as well as functional wetting and electrical properties of $\mathrm{TiO}_{2} / \mathrm{GO} / \mathrm{Ag}$ nanocomposite thin films. Our results demonstrate that both wetting and electrical properties of the $\mathrm{TiO}_{2} / \mathrm{GO}$ nanocomposite thin films can be simultaneously engineered through the addition of GO and Ag nanoparticles (NPs). Besides environmental applications conductive layers with improved wetting and antimicrobial properties are of interest for many practical applications as biosensing [18], smart fabric sensors and electronic textile technologies [19, 20], as well as flexible and transparent optoelectronic devices [21].

\section{Experimental}

The laser transfer and immobilization experiments were performed inside a stainless steel deposition chamber. A pulsed UV $\mathrm{KrF}^{*}\left(\lambda=248 \mathrm{~nm}, \tau_{\mathrm{FWHM}} \leq 25 \mathrm{~ns}, v=10 \mathrm{~Hz}\right)$ COMPexPro 205 Lambda Physics excimer laser source was used for the irradiation of the composite MAPLE targets. Anatase phase $\mathrm{TiO}_{2}$ NPs with an average diameter below 25 nm (Sigma-Aldrich, 99.7\%), GO platelets with about $1 \mu \mathrm{m}^{2}$ surface area (NanoInnova Technologies, Spain) and Ag NPs with an average diameter below $100 \mathrm{~nm}$ (Sigma-Aldrich, 99.5\%) were used as base materials for the preparation of the MAPLE targets. Dispersions in distilled water of $1 \mathrm{wt} . \% \mathrm{TiO}_{2} \mathrm{NPs}, 1 \mathrm{wt} . \% \mathrm{TiO}_{2}$ NPs and Ag NPs with concentrations in the range (1-5) wt.\% as well as 1 wt $\% \mathrm{TiO}_{2} \mathrm{NPs}, 5 \mathrm{wt} \%$ GO platelets, and Ag NPs with concentrations in the range (1-5) wt.\% were prepared. After 
sonication the dispersions were introduced into a special double wall target holder and flash-frozen by circulating liquid nitrogen inside the holder walls. The targets were kept frozen during the irradiation experiments. The laser fluence at the target surface was set at $400 \mathrm{~mJ} / \mathrm{cm}^{2}$. A number of $10^{4}$ subsequent laser pulses were applied for the deposition of each sample. BK7 glass plates with $1 \times 1 \mathrm{~cm}^{2}$ surface area were used as substrates, placed parallel to the target at a separation distance of $4 \mathrm{~cm}$. During the experiments the substrates were kept at a constant temperature of $50{ }^{\circ} \mathrm{C}$ with the aid of a PID Excel temperature controller. Before each experiment the irradiation chamber was evacuated down to a residual pressure of $10^{-3} \mathrm{~Pa}$. The experiments were performed in controlled $\mathrm{O}_{2}$ atmosphere at 2 and $20 \mathrm{~Pa}$ pressure values.

The surface morphology of the deposited films was investigated by scanning electron microscopy (FE-SEM) with a Hitachi S-3400 instrument, operated at $15 \mathrm{kV}$ acceleration voltage and atomic force microscopy (AFM) using a NT-MDT model BL222RNTE equipment with images taken in semicontact mode with Si-tips (NSG10, force constant $0.15 \mathrm{~N} / \mathrm{m}$, tip radius $10 \mathrm{~nm}$ ). The chemical bonds between the elements of the deposited nanocomposite thin films were investigated by X-ray photoelectron spectroscopy (XPS). The XPS studies were performed with the aid of a SPECS XPS spectrometer (SPECS Surface Nano Analysis GmbH, Berlin, Germany), based on Phoibos 150 electron energy analyzer operated in constant energy mode. A non-monochromatic X-ray source $(\mathrm{MgK} \alpha$ line of $1253.6 \mathrm{eV}$ ) was used for excitation and was run with $12.5 \mathrm{kV}$ anode bias and $20 \mathrm{~mA}$ emission current (250W). The measurements were made in an ultrahigh vacuum at a residual pressure of around $10^{-7} \mathrm{~Pa}$. A SPECS FG20 flood gun was used for the charge neutralization. Highresolution spectra were acquired over smaller ranges of $20 \mathrm{eV}$ using $0.05 \mathrm{eV}$ step at $10 \mathrm{eV}$ pass energy. The binding energy scale of the spectra has been corrected using the C1s line. A binding energy of $284.8 \mathrm{eV}$ corresponding to the $\mathrm{C}=\mathrm{C}$ bonds has been assumed to this purpose. The obtained data were analyzed using SDP32 XPS software (version 7.0; XPS International, Mountain View, CA). Contact angle investigations were performed by the sessile drop method using an OCA20 contact angle system from DataPhysics Instruments. To this aim a $3 \mu \mathrm{L}$ volume liquid droplet was placed with $0.5 \mu \mathrm{L} / \mathrm{s}$ steps on the surface of the synthesized thin films. Contact angles were measured during 5 minutes and data were recorded with 1 second step. The electrical properties of the nanocomposite thin films were studied by sheet resistance measurements over $1 \times 1 \mathrm{~mm}^{2}$ film areas, with a micro-probe station and a Keithley 2612B source-meter system. The micro-probe station was equipped with tips with a diameter of $10 \mu \mathrm{m}$.

3. Results and discussion 
The FE-SEM micrographs of the $\mathrm{TiO}_{2} / \mathrm{Ag}$ as well as $\mathrm{TiO}_{2} / \mathrm{Ag} / \mathrm{GO}$ composite thin films deposited in $20 \mathrm{~Pa} \mathrm{O}_{2}$ pressure are presented in Fig. 1(a,b). The $\mathrm{TiO}_{2}$ and Ag NPs as well as GO platelets concentrations in the MAPLE targets were 1, 5, and $5 \mathrm{wt} \%$, respectively. The surface of the $\mathrm{TiO}_{2} / \mathrm{Ag}$ film (Fig. 1a) is composed by large particles with diameters in the several hundreds of nm up to $1 \mu \mathrm{m}$ as well as smaller NPs with diameters below $100 \mathrm{~nm}$. As it can be observed, significant part of the particles are larger as compared to the starting $\mathrm{TiO}_{2}$ and Ag NPs used for the preparation of the MAPLE targets, with diameters of around 20 and $100 \mathrm{~nm}$, respectively. The spherical shape of the particles suggests that they are formed in liquid phase through the coalescence of the initial NPs, molten under the action of the laser pulses. On the surface of the film $\mathrm{TiO}_{2} / \mathrm{Ag} / \mathrm{GO}$ composite film large, micron sized aggregates composed of GO irregular shape platelets, spherical particles, as well as NPs with diameters below $100 \mathrm{~nm}$ can be distinguished (Fig. 1b).
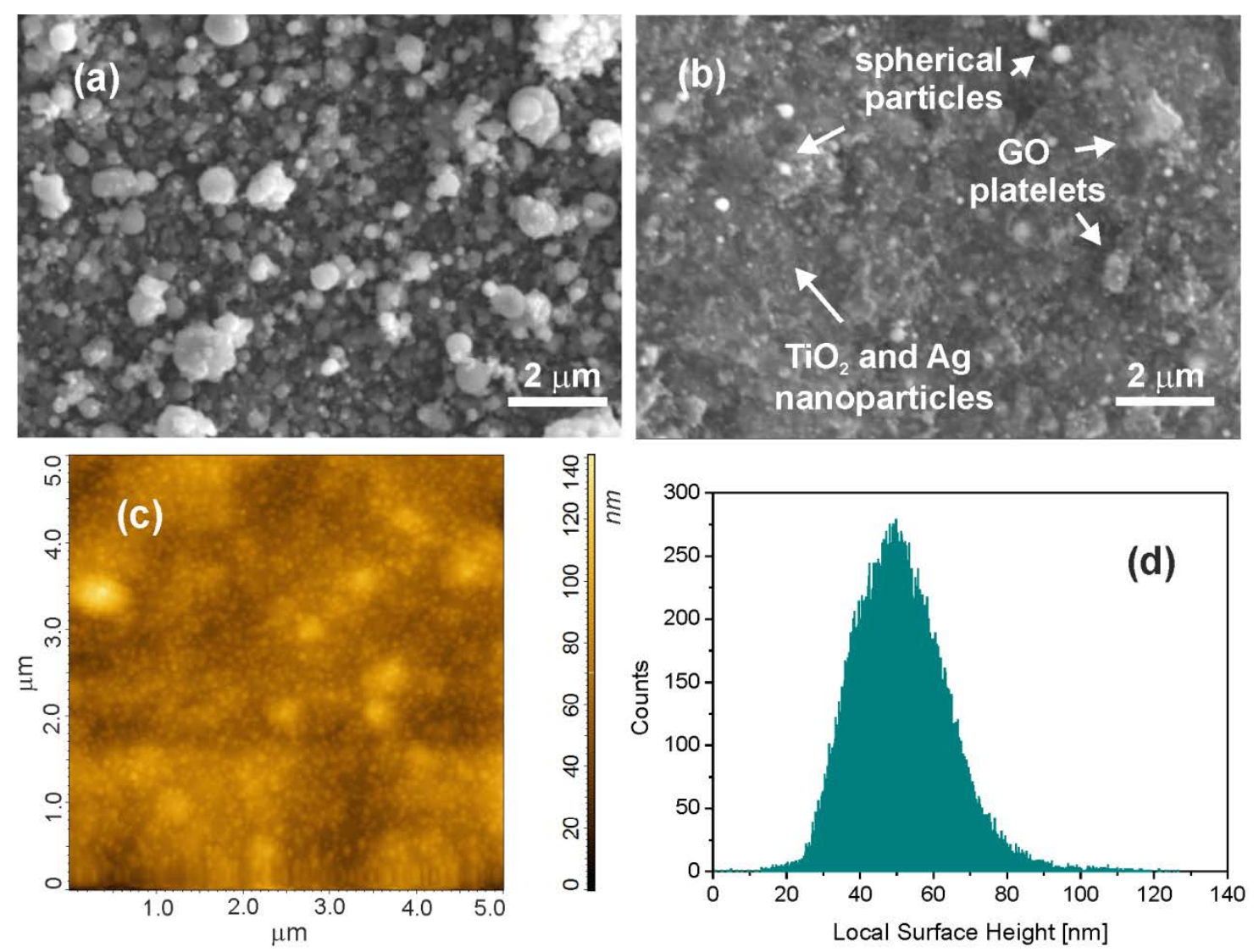

Fig. 1. (a) FE-SEM micrograph of $\mathrm{TiO}_{2} / \mathrm{Ag}$ nanocomposite thin film obtained by the irradiation of a MAPLE target containing 1 wt.\% $\mathrm{TiO}_{2}$ nanoparticles and 5 wt.\% Ag, (b) FE-SEM, (c) AFM images, and (d) local surface height histogram of $\mathrm{TiO}_{2} / \mathrm{GO} / \mathrm{Ag}$ nanocomposite thin film obtained by the irradiation of a MAPLE target containing 1 wt.\% $\mathrm{TiO}_{2}$ nanoparticles, $5 \mathrm{wt} \%$ GO platelets, and 5 wt.\% Ag deposited in $20 \mathrm{~Pa} \mathrm{O}_{2}$ pressure.

AFM investigations were performed to further evaluate the surface morphology of the composite films. As Fig. 1c shows, the large irregular shape aggregates and spherical particles are covered by 
smaller, tens of nm, up to $100 \mathrm{~nm}$ sized NPs, the average local surface height being of around 50 nm (Fig. 1d). The surface morphology of the films was found to not be significantly influenced by the ambient gas pressure value.

Fig. 2 shows the Ti2p (a) and Ag3d (b) XPS doublets of the $\mathrm{TiO}_{2} / \mathrm{GO} / \mathrm{Ag}$ composite thin film obtained at $2 \mathrm{~Pa} \mathrm{O}_{2}$ pressure. The Ti2 $\mathrm{p}_{3 / 2}$ and $\mathrm{T}_{2} \mathrm{p}_{1 / 2}$ lines are located at 459.4 and $465.1 \mathrm{eV}$, corresponding to the binding energy values reported in the literature for stoichiometric $\mathrm{TiO}_{2}[22$, 23]. The symmetrical shape of the $\mathrm{Ti} 2 \mathrm{p}_{3 / 2}$ and $\mathrm{Ti} 2 \mathrm{p}_{1 / 2}$ lines and their positions indicate that no $\mathrm{TiO}_{2-}$ x suboxides, titanium oxides with Ti species of lower oxidation state, or Ti-C bonds were formed during the laser irradiation and transfer processes. As known, the binding energy values of both Ti$\mathrm{O}$ bonds corresponding to $\mathrm{TiO}_{2-\mathrm{x}}$ suboxides and $\mathrm{Ti}-\mathrm{C}$ bonds are situated at lower values as compared to Ti-O bond of stoichiometric $\mathrm{TiO}_{2}$ [22-24]. The Ag3d region is composed by two main peaks, belonging to the $A g 3 \mathrm{~d}_{5 / 2}$ and $A g 3 \mathrm{~d}_{3 / 2}$ doublet. The $A g 3 \mathrm{~d}_{5 / 2}$ and $A g 3 \mathrm{~d}_{3 / 2}$ peak positions at 368.8 and $374.8 \mathrm{eV}$ are in good agreement with the values reported in literature for metallic silver [25]. We note that the shape and binding energy values of the Ti2p and Ag3d peaks are very similar for all $\mathrm{TiO}_{2} / \mathrm{Ag}$ and $\mathrm{TiO}_{2} / \mathrm{GO} / \mathrm{Ag}$ nanocomposite films, independently on the ambient oxygen pressure value or the Ag concentration in the composite MAPLE targets.
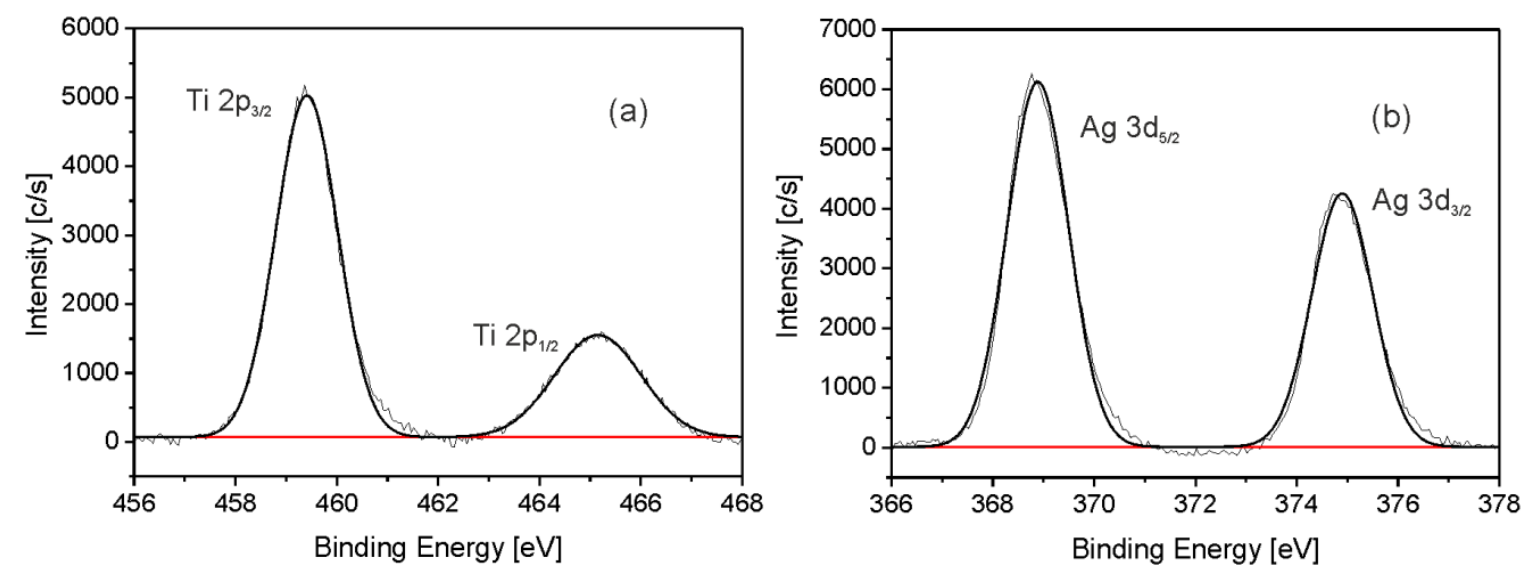

Fig. 2. Ti2p and Ag3d XPS spectra of $\mathrm{TiO}_{2} / \mathrm{GO} / \mathrm{Ag}$ nanocomposite thin film obtained by the irradiation of a MAPLE target containing 1 wt. $\% \mathrm{TiO}_{2}$ nanoparticles, 5 wt.\% GO flakes and 1 wt.\% Ag in $2 \mathrm{~Pa} \mathrm{O}_{2}$ pressure. 
In Fig. 3 we present the C1s spectrum of a reference GO drop-cast sample (Fig. 3a) and of the $\mathrm{TiO}_{2} / \mathrm{GO} / \mathrm{Ag}$ nanocomposite films deposited in 20 (Fig. 3b) and $2 \mathrm{~Pa}$ (Fig. 3c) $\mathrm{O}_{2}$ pressure.
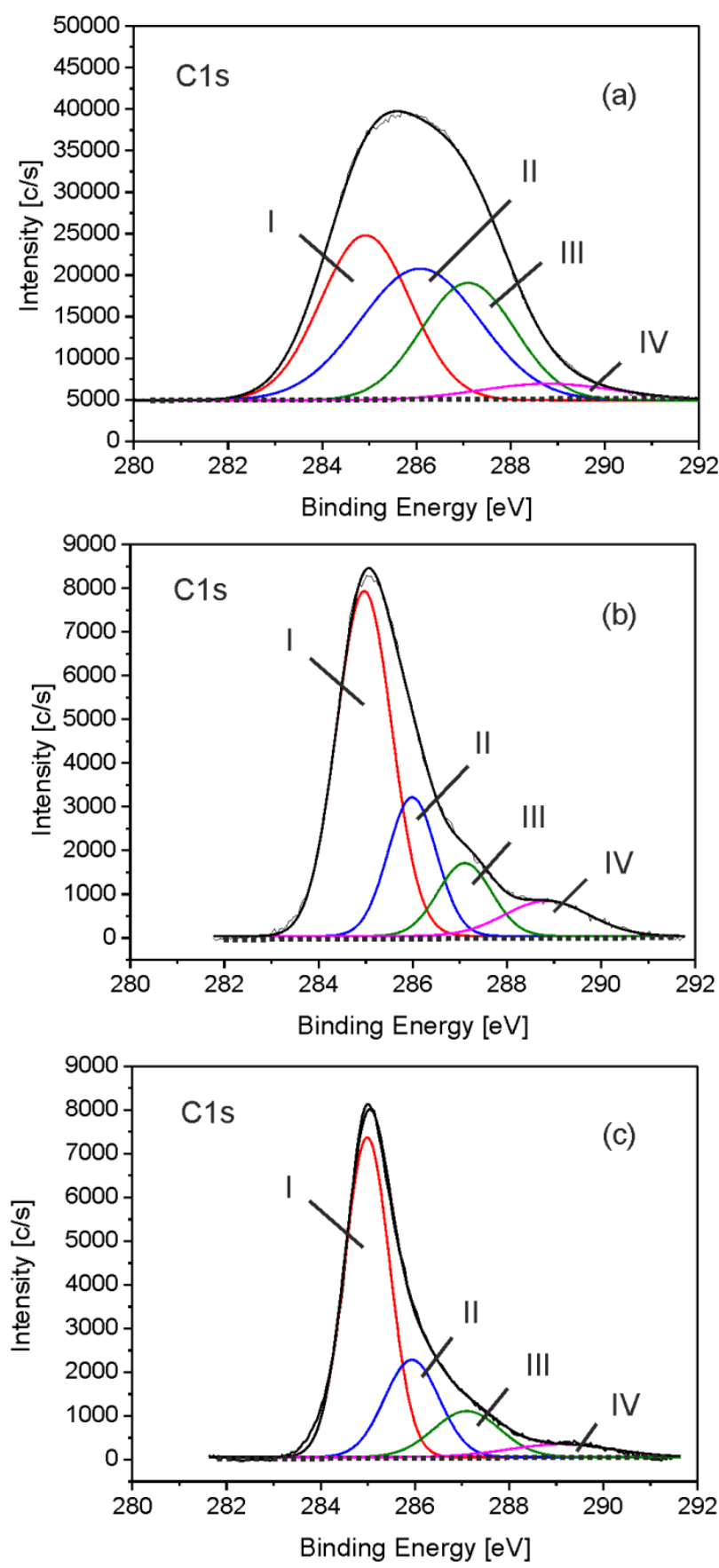

Fig. 3. C1s XPS spectra of drop cast GO reference sample (a) and $\mathrm{TiO}_{2} / \mathrm{GO} / \mathrm{Ag}$ nanocomposite thin film obtained by the irradiation of a MAPLE target containing 1 wt.\% $\mathrm{TiO}_{2}$ nanoparticles, 5 wt.\% GO flakes, and 1 wt.\% Ag in (b) 20 and (c) $2 \mathrm{~Pa} \mathrm{O}_{2}$ pressure. 
The reference GO drop-cast sample was obtained from a dispersion in distilled water of 5 wt.\% GO platelets identical to those used for the preparation of the MAPLE targets. Each C1s spectra was deconvoluted in four lines corresponding to (I) $\mathrm{sp}^{2} \mathrm{C}=\mathrm{C}$ bonds centred at $284.8 \mathrm{eV}$ binding energy, and oxygen containing functional groups (II-IV) situated at higher binding energy values [26-28]. The (I) $\mathrm{sp}^{2} \mathrm{C}=\mathrm{C}$ bonds correspond to the graphite-like $\mathrm{sp}^{2} \mathrm{C}$ of the conjugated honeycomb lattice. The peaks centred at higher binding energy values are attributed to C-O singe bonds (II) of C-O-C epoxy and $\mathrm{C}-\mathrm{OH}$ hydroxyl groups, as well as $\mathrm{C}=\mathrm{O}$ double bonds of $\mathrm{C}=\mathrm{O}$ carbonyl (III) and $\mathrm{O}-\mathrm{C}=\mathrm{O}$ carboxyl groups (IV) [26-28]. The binding energy values of the deconvolution lines of the C1s XPS spectra corresponding to the $\mathrm{TiO}_{2} / \mathrm{GO} / \mathrm{Au}$ nanocomposite thin films deposited in 20 (Fig. 3b) and 2 $\mathrm{Pa} \mathrm{O}_{2}$ atmosphere (Fig. 3c) are very similar to those of the $\mathrm{C} 1 \mathrm{~s}$ spectrum of the reference GO sample. However, the intensity of the peaks assigned to $\mathrm{C}-\mathrm{O}$ single and $\mathrm{C}=\mathrm{O}$ double bonds of the oxygen functional groups is gradually reduced as compared to the GO sample with the decrease of the ambient oxygen pressure value. This feature indicates a diminishment of the number of the oxygen functional groups under UV laser irradiation, leading to the formation of reduced GO (rGO) structures. The reduction of GO is more effective in low oxygen pressure. The larger number of C$\mathrm{O}$ and $\mathrm{C}=\mathrm{O}$ bonds in high oxygen pressure can be attributed to possible re-oxidation processes during the transit of the laser ablated material from the target towards the substrate surface.

The initial water contact angles as well as their evolution under UV illumination of pure $\mathrm{TiO}_{2}$ thin film as well as $\mathrm{TiO}_{2} / \mathrm{Ag}$ and $\mathrm{TiO}_{2} / \mathrm{Ag} / \mathrm{GO}$ nanocomposite films are presented in Fig. 4. The pure $\mathrm{TiO}_{2}$ surface is highly hydrophobic (Fig. 4a). As can be observed, the contact angle of the $\mathrm{TiO}_{2}$ thin film decreases progressively under UV illumination. This feature is characteristic for $\mathrm{TiO}_{2}$ surfaces and was related to the reduction of $\mathrm{Ti}^{4+}$ to $\mathrm{Ti}^{3+}$ under UV light irradiation and creation of oxygen vacancies [5, 29, 30]. Previous results indicate that oxygen vacancy states affect surface adsorption and reactivity of $\mathrm{O}_{2}$ and $\mathrm{H}_{2} \mathrm{O}$ on the $\mathrm{TiO}_{2}$ surface $[5,29,30]$. It was demonstrated that chemical dissociation of water molecules is energetically favoured on defective $\mathrm{TiO}_{2}$ surfaces, whereas $\mathrm{H}_{2} \mathrm{O}$ molecules are only physically adsorbed on stoichiometric $\mathrm{TiO}_{2}$ [5]. A direct correlation was found to exist between oxygen vacancies before water exposure and surface hydroxyl groups after exposure [30]. Through the dissociative adsorption of water molecules hydroxyl groups are created, resulting in a hydroxylated surface which enhances polar properties and hydrophilicity [5, 31]. Photoinduced wettability conversion phenomenon of $\mathrm{TiO}_{2}$ surfaces can be associated also to their photocatalytic activity [13, 32]. It was found that besides the described structural changes, the removal of organic contamination present on air-exposed of $\mathrm{TiO}_{2}$ surfaces, contributes to the 
improvement of surface wettability and hydrophobic to hydrophilic conversion under UV light irradiation [13, 32].

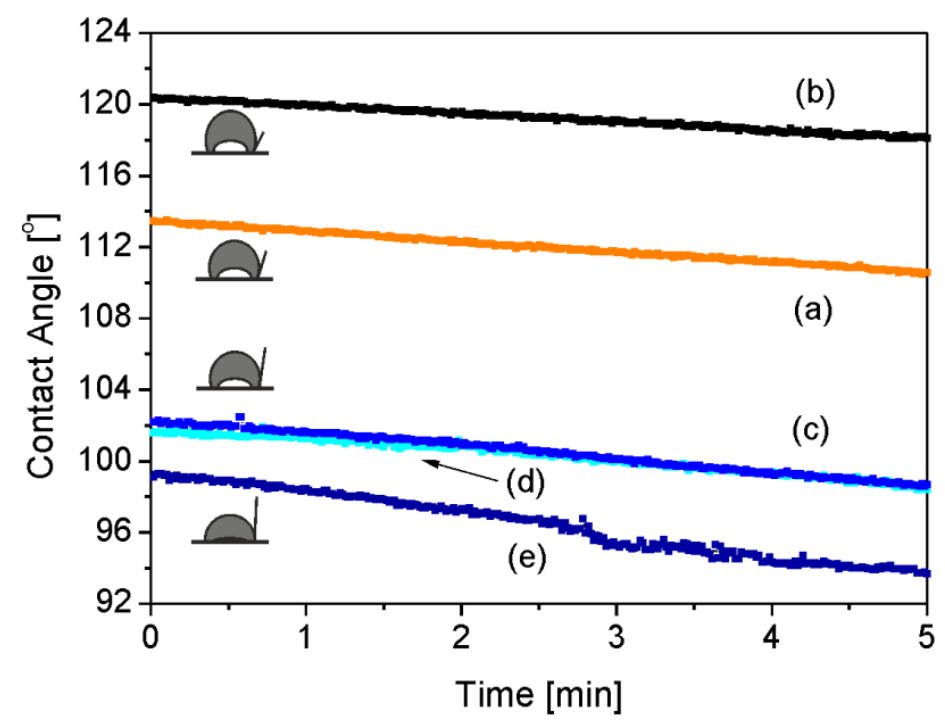

Fig. 4. Water contact angles evolution under UV light irradiation as a function of time for (a) $\mathrm{TiO}_{2}$ thin film obtained using a MAPLE target containing $1 \mathrm{wt} \% \mathrm{TiO}_{2} \mathrm{NPs}$ and nanocomposite thin film obtained using a MAPLE target containing (b) $1 \mathrm{wt} \% \mathrm{TiO}_{2}$ NPs and $5 \mathrm{wt} . \%$ GO platelets, (c) $1 \mathrm{wt} \%$ $\mathrm{TiO}_{2}$ NPs, 5 wt.\% GO platelets, and $1 \mathrm{wt} \%$ Ag, (d) $1 \mathrm{wt} \% \mathrm{TiO}_{2}$ NPs, 5 wt.\% GO platelets, and 2 wt\% Ag, as well as (e) 1 wt $\% \mathrm{TiO}_{2}$ NPs, 5 wt.\% GO platelets, and $5 \mathrm{wt} \%$ Ag deposited at 2 Pa $\mathrm{O}_{2}$ pressure.

The water contact angle of the $\mathrm{TiO}_{2} / \mathrm{GO}$ nanocomposite thin films (Fig. 4b) is higher than that of pure $\mathrm{TiO}_{2}$ (Fig. 4a). The enhanced hydrophobic character can be attributed to the reduction of oxygen containing functional groups of the GO platelets during laser processing and immobilization, as was evidenced by XPS investigations (Fig. 3). The efficiency of the reduction process is directly related to the $\mathrm{O}_{2}$ pressure inside the irradiation chamber (Fig. 3b, c). Through the diminishment of the $\mathrm{O}_{2}$ pressure the oxygen containing functional groups are gradually reduced, leading to the formation of hydrophobic graphene-like materials. Indeed, $\mathrm{TiO}_{2} / \mathrm{GO}$ layers deposited at high $\mathrm{O}_{2}$ pressure but under otherwise identical experimental conditions are characterised by much lower, around $50^{\circ}$ water contact angle [33]. Similarly to the pure $\mathrm{TiO}_{2}$ film, the water contact angle of the $\mathrm{TiO}_{2} / \mathrm{GO}$ nanocomposite layer decreases upon UV light irradiation. According to recent investigations, reversible wettability transition in graphene from hydrophobic to hydrophilic can be obtained under alternative UV light irradiation and air storage [34, 35], similar as for $\mathrm{TiO}_{2}$ surfaces. Density functional theory calculations showed that graphene become highly hydrophilic after exposure to UV irradiation due to the dissociative adsorption of ambient $\mathrm{H}_{2} \mathrm{O}$ molecules [34]. 
Conversely, the addition of Ag NPs to the $\mathrm{TiO}_{2} / \mathrm{GO}$ composites led to the gradual diminishment of the water contact angle with the increase of the Ag concentration in the targets (Fig. 4c-e). However, the surfaces still preserve their hydrophobic character. Loading of noble metal NPs was found to diminish the water contact angle of metal oxide semiconductor surfaces [36, 37]. The adsorption energy of $\mathrm{H}_{2} \mathrm{O}$ molecules on noble metal $\mathrm{NPs}$ loaded $\mathrm{TiO}_{2}$ was reported to be lower than the adsorption energy of $\mathrm{H}_{2} \mathrm{O}$ on bare $\mathrm{TiO}_{2}$ [37].

The electron transfer and reaction mechanisms taking place on the surface of the $\mathrm{TiO}_{2} / \mathrm{GO} / \mathrm{Ag}$ nanocomposite thin films under UV light illumination are presented schematically in Fig. 5.
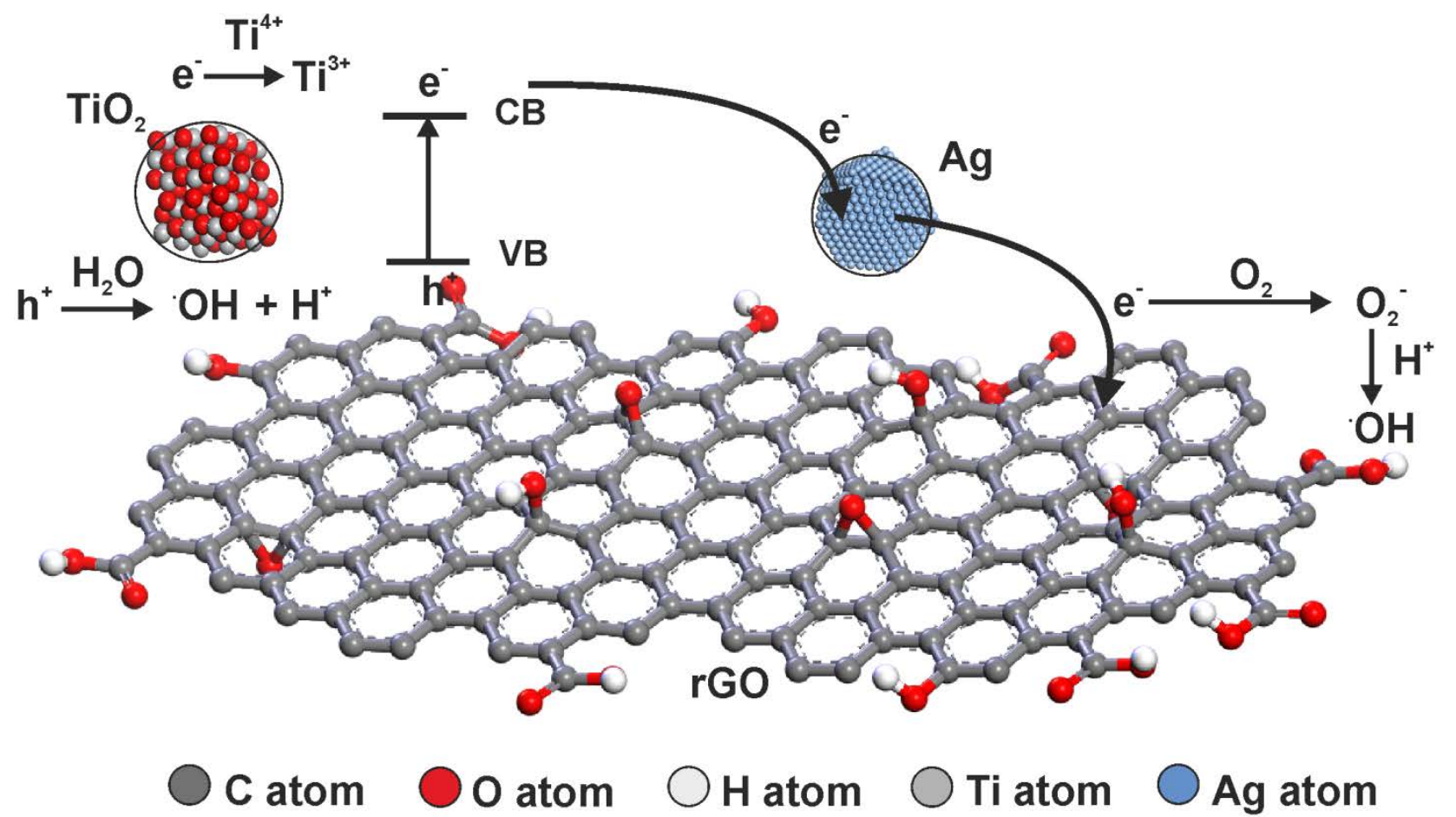

Fig. 5. Schematic representation of electron transfer and reaction mechanisms taking place on the surface of the $\mathrm{TiO}_{2} / \mathrm{GO} / \mathrm{Ag}$ nanocomposite thin films.

Ag NPs in the $\mathrm{TiO}_{2} / \mathrm{GO} / \mathrm{Ag}$ system prevent electrons-holes pairs recombination acting as electron scavenger and contribute to the generation of $\mathrm{O}_{2}^{-}$and $\mathrm{Ti}^{3+}$ :

$\mathrm{TiO}_{2}+h v \rightarrow \mathrm{TiO}_{2}\left(\mathrm{e}^{-}+\mathrm{h}^{+}\right)$

$\mathrm{TiO}_{2}\left(\mathrm{e}^{-}\right)+\mathrm{Ag} \rightarrow \mathrm{Ag}\left(\mathrm{e}^{-}\right)$

$\operatorname{Ag}\left(\mathrm{e}^{-}\right)+\mathrm{Ti}^{4+} \rightarrow \mathrm{Ag}+\mathrm{Ti}^{3+}$ 
$\mathrm{Ag}\left(\mathrm{e}^{-}\right)+\mathrm{O}_{2} \rightarrow \mathrm{Ag}+\mathrm{O}_{2}^{-}$

The photogenerated electrons can be transferred and transported also across the rGO platelets:

$\mathrm{TiO}_{2}\left(\mathrm{e}^{-}\right)+\mathrm{rGO} \rightarrow \mathrm{rGO}\left(\mathrm{e}^{-}\right)$

$\mathrm{rGO}\left(\mathrm{e}^{-}\right)+\mathrm{O}_{2} \rightarrow \mathrm{rGO}+\mathrm{O}_{2}^{-}$

The positive holes can oxidize water molecules adsorbed at the films' surface to produce hydroxyl radicals through the dissociative adsorption of $\mathrm{H}_{2} \mathrm{O}$ molecules:

$\mathrm{TiO}_{2}\left(\mathrm{~h}^{+}\right)+\mathrm{H}_{2} \mathrm{O} \rightarrow{ }^{\cdot} \mathrm{OH}+\mathrm{H}^{+}$

Hydroxyl radicals are created also through the reaction of $\mathrm{O}_{2}{ }^{-}$with $\mathrm{H}^{+}$to form $\mathrm{H}_{2} \mathrm{O}_{2} \cdot \mathrm{H}_{2} \mathrm{O}_{2}$ is a source of hydroxyl radicals making the surface more hydrophilic through the reaction:

$2 \mathrm{O}_{2}^{-}+2 \mathrm{H}^{+} \rightarrow 2 \mathrm{HO}_{2}{ }^{\cdot} \rightarrow \mathrm{H}_{2} \mathrm{O}_{2}+\mathrm{O}_{2} \rightarrow 2^{\circ} \mathrm{OH}$

The electrical resistivity of the $\mathrm{TiO}_{2} / \mathrm{Ag}$ and $\mathrm{TiO}_{2} / \mathrm{GO} / \mathrm{Ag}$ nanocomposite thin films are presented in Fig. 6. The $\mathrm{TiO}_{2} / \mathrm{Ag}$ thin film obtained from MAPLE targets containing only $1 \mathrm{wt} . \% \mathrm{Ag}$ NPs is very high, around $0.4 \mathrm{M} \Omega \mathrm{cm}$, but around $10^{3}$ times lower that the resistivity measured for pure $\mathrm{TiO}_{2}$ thin films [38]. The resistivity value of the $\mathrm{TiO}_{2} / \mathrm{Ag}$ nanocomposites decreases with the increase of the Ag NPs concentration in the targets, until around $250 \Omega \mathrm{cm}$ for the highest, $5 \mathrm{wt} \%$ Ag NPs concentration. On the other hand, significant decrease of the electrical resistivity takes place upon the addition of GO platelets, until around 9, 7, and $3 \Omega \mathrm{cm}$ for Ag NPs concentrations of 1 , 2, and 5 wt.\% in case of the irradiations performed in $20 \mathrm{~Pa} \mathrm{O}_{2}$ pressure. Further diminishment of the electrical resistivity of the $\mathrm{TiO}_{2} / \mathrm{GO} / \mathrm{Ag}$ nanocomposite thin films was observed with the decrease of the $\mathrm{O}_{2}$ pressure to $2 \mathrm{~Pa}$. The low resistivity values can be assigned to decrease in the oxygen content of the GO platelets, and formation of graphene-like structures during laser processing and immobilization, as observed also by XPS investigation (Fig. 3b, c). Our lowest resistivity values are similar to that measured for $\mathrm{TiO}_{2} / \mathrm{GO}$ composites reduced by post-deposition treatments of $\mathrm{TiO}_{2} / \mathrm{GO}$ films using UV light irradiation [39], and GO films reduced chemically through hydrazine hydrate vapors [40,41] or by thermal annealing [42]. Our laser based technique is a single-step synthesis and deposition method, without the necessity of post-deposition heat or chemical treatments. The growth process is performed at room temperature and it does not imply the use of harmful chemical substances. 


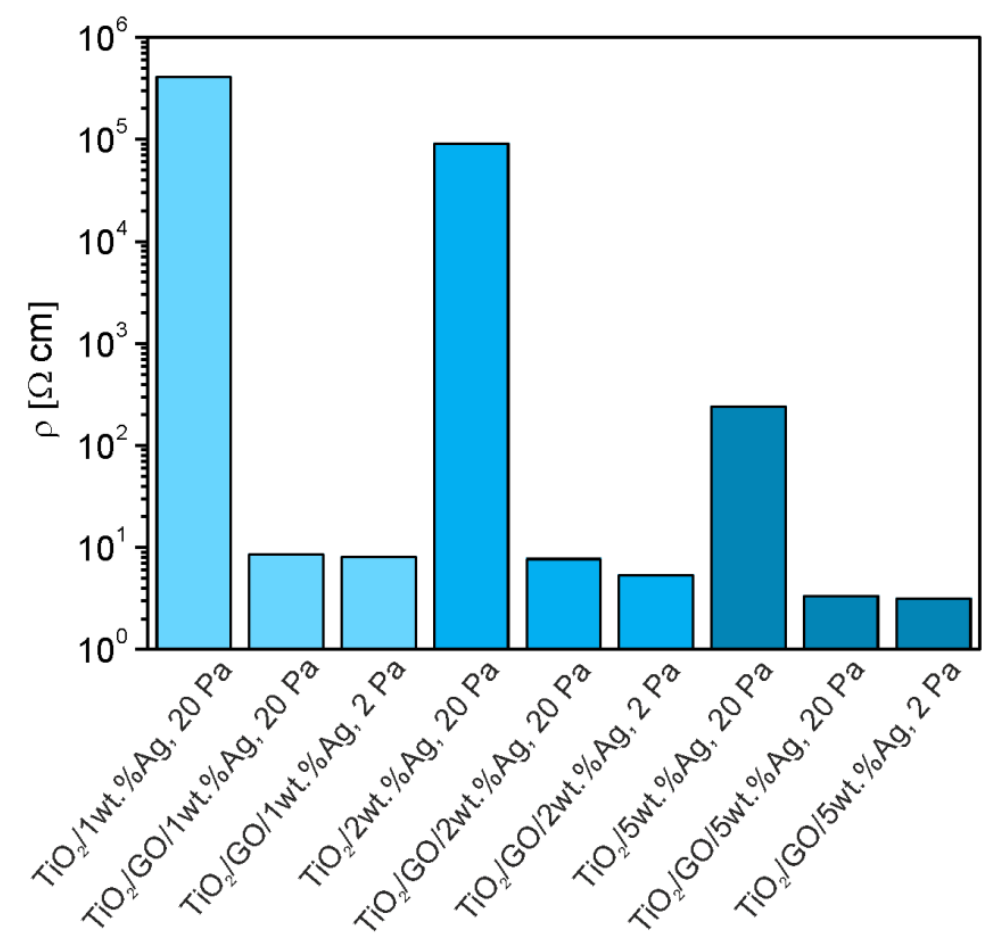

Fig. 6. Electrical resistivity of $\mathrm{TiO}_{2} / \mathrm{Ag}$ and $\mathrm{TiO}_{2} / \mathrm{GO} / \mathrm{Ag}$ nanocomposite thin films obtained at 20 and $2 \mathrm{~Pa}$ ambient $\mathrm{O}_{2}$ pressure.

Hydrophobic and highly conductive surface coatings are especially valuable for many engineering applications. Through MAPLE technique complex multicomponent materials can be synthesized and deposited on practically any type of substrate material. The functional, wetting and electrical properties of the coatings can be controlled and tailored through the concentration of the base materials in the target solutions and ambient gas pressure.

\section{Conclusions}

Highly conductive and hydrophobic $\mathrm{TiO}_{2} / \mathrm{GO} / \mathrm{Ag}$ nanocomposite coatings were prepared by simple one-step environmentally friendly laser technique. $\mathrm{TiO}_{2}$ and $\mathrm{Ag}$ NPs, as well as GO platelets were used as base materials for the preparation of the MAPLE targets. Our XPS investigations show that GO undergoes partial reduction under the action of the laser pulses. The hydrophobic character of the coatings and their low resistivity values can be assigned to decrease in the oxygen content of the GO platelets during the laser immobilization process. The addition of Ag NPs contributes to the improvement of the coatings electrical conductivity. The synergistic effect, bridging together two 
valuable functional properties may be useful in many applications as protection of electrical devices working in high humidity circumstances from short-circuits and corrosion, solar panels, implantable sensor systems for medical applications, fluid transportation, electrodes for fuel cells, nonfouling surfaces.

\section{Acknowledgments}

The authors acknowledge the financial support from the Executive Unit for Financing Higher

Education, Research, Development, and Innovation of the Romanian Ministry of Education and Scientific Research under the contract PN-IIPT-PCCA-2011-3.2-1235 and the Spanish Ministry of Economy and Competitiveness under the contract ENE2014-56109-C3-3-R. 


\section{References}

1. Lide, D. R. ed. Handbook of chemistry and physics; 71st edition, CRC: Boca Raton, FL, 1991.

2. Crossland, E. J. W.; Noel, N.; Sivaram, V.; Leijtens, T.; Alexander-Webber, J. A.; Snaith, H. J. Mesoporous $\mathrm{TiO}_{2}$ single crystals delivering enhanced mobility and optoelectronic device performance. Nature 2013, 495, 215-219.

3. Honda, K.; Fujishima, A. Electrochemical photolysis of water at a semiconductor electrode. Nature 1972, 238, 37-38.

4. Schneider, J.; Matsuoka, M.; Takeuchi, M.; Zhang, J.; Horiuchi, Y.; Anpo, M.; Bahnemann, D. W. Understanding $\mathrm{TiO}_{2}$ photocatalysis: mechanisms and materials. Chem. Rev. 2014, 114, 9919-9986.

5. Pan, X.; Yang, M. Q.; Fu, X.; Zhang, N.; Xu, Y. J. Defective $\mathrm{TiO}_{2}$ with oxygen vacancies: synthesis, properties, and photocatalytic applications. Nanoscale, 2013, 5, 3601-3614.

6. Serpone, N.; Emeline, A. V. Semiconductor photocatalysis - past, present, and future outlook. J. Phys. Chem. Lett. 2012, 3, 673-677.

7. Schneider, J.; Matsuoka, M.; Takeuchi, M.; Zhang, J.; Horiuchi, Y.; Anpo, M.; Bahnemann, D. W. Understanding $\mathrm{TiO}_{2}$ Photocatalysis: Mechanisms and Materials. Chem. Rev. 2014, 114, 9919-9986.

8. Sauthier, G.; Perez del Pino, A.; Figueras, A.; György, E. Synthesis and characterization of Ag nanoparticles and Ag loaded $\mathrm{TiO}_{2}$ photocatalysts. J. Am. Ceram. Soc., 2011, 94, 37803786.

9. Long, R. Electronic Structure of Semiconducting and Metallic Tubes in $\mathrm{TiO}_{2} /$ Carbon Nanotube Heterojunctions: Density Functional Theory Calculations. J. Phys. Chem. Lett. $2013,4,1340-1346$.

10. Xiang, Q.; Yu, J.; Jaroniec, M. Graphene-based semiconductor photocatalysts. Chem. Soc. Rev. 2012, 41, 782-796.

11. Datcu, A.; Duta, L.; Perez del Pino, A.; Logofatu, C.; Luculescu, C.; Duta, A.; Perniu, D.; György, E. One-step preparation of nitrogen doped titanium oxide/Au/reduced graphene oxide composite thin films for photocatalytic applications. RSC Adv. 2015, 5, 49771-49779.

12. Kou, L.; Gao, C. Making silica nanoparticle-covered graphene oxide nanohybrids as general builind blocks for large-area superhydrophilic coatings. Nanoscale 2011, 3, 519-528.

13. Anandan, S.; Rao, T. N.; Sathish, M.; Rangappa, D.; Honma, I.; Miyauchi, M. Superhydrophilic graphene-loaded $\mathrm{TiO}_{2}$ thin film for self-cleaning applications. ACS Appl. Mater. Interfaces 2013, 5, 207-212. 
14. Zhu, J.; Cao, Y.; He, J. Facile fabrication of transparent, broadband photoresponse, selfcleaning multifunctional graphene- $\mathrm{TiO}_{2}$ hybrid films. J. Colloid Interface Sci. 2014, 420, 119-126

15. Asthana, A.; Maitra, T.; Büchel, R.; Tiwari, M. K.; Poulikakos, D. Multifunctional superhydrophobic polymer/carbon nanocomposites: graphene, carbon nanotubes, or carbon black? ACS Appl. Mater. Interfaces 2016, dx.doi.org/10.1021/am501649w.

16. Eason R. ed. Pulsed laser deposition of thin films: applications-led growth of functional materials; Wiley: Hoboken, New Jersey, 2007.

17. Piqué, A. The matrix-assisted pulsed laser evaporation (MAPLE) process: origins and future directions. Appl. Phys. A: Mater. Sci. Process., 2011, 105, 517-528.

18. Puri, N.; Niazi, A.; Srivastava A. K.; Rajesh, Synthesis and characterization of reduced graphene oxide supported gold nanoparticles-poly (pyrrole-Co-Pyrrolepropylic acid) nanocomposite based electrochemical biosensors. Appl. Biochem. Biotechnol. 2014, 174, 911-925.

19. Castano, L. M.; Flatau, A. B. Smart fabric sensors and e-textile technologies: a review. Smart Mater. Struct. 2014, 23, 053001(1-27).

20. Joung, Y. S.; Buie, C. R. Antiwetting fabric produced by a combination of layer-by-layer assembly and electrophoretic deposition of hydrophobic nanoparticles. ACS Appl. Mater. Interfaces 2015, 7, 20100-20110.

21. Zheng, Q.; Li, Z.; Yang, J.; Kim, J. K. Graphene oxide-based transparent conductive films. Progress in Materials Science. 2014, 64, 200-247.

22. Jobin, M.; Taborelli, M.; Descouts, P. Structural characterization of oxidized titanium surfaces. J. Appl. Phys. 1995, 77, 5149

23. Lu, G.; Bernasek, S. L.; Schwartz, J. Oxidation of a polycrystalline titanium surface by oxygen and water. Surf. Sci. 2000, 458, 80-90.

24. Li, Y.; Hwang, D. S.; Lee, N. H.; Kim, S. J. Synthesis and characterization of carbon-doped titania as an artificial solar light sensitive photocatalyst. Chem. Phys. Lett. 2005, 404, 2529.

25. Seah, M. P.; Smith, G. C.; Anthony, M. T. AES: Energy calibration of electron spectrometers. I - an absolute, traceable energy calibration and the provision of atomic reference line energies, Surf. Interface Anal. 15, 293 (1990).

26. Yang, D.; Velamakanni, A.; Bozoklu, G.; Park, S.; Stoller, M.; Piner, R. D.; Stankovich, S.; Jung, I.; Field, D. A.; Ventrice Jr, C. A.; Ruoff, S. Chemical analysis of graphene oxide films after heat and chemical treatments by X-ray photoelectron and Micro-Raman spectroscopy. Carbon, 2009, 47, 145-152. 
27. Matsumoto, Y.; Koinuma, M.; Ida, S.; Hayami, S.; Taniguchi, T.; Hatekeyama, K.; Tateishi, H.; Watanabe, Y.; Amano, S. Photoreaction of Graphene Oxide Nanosheets in Water. J. Phys. Chem. C, 2011, 115, 19280-19286.

28. Pei, S.; Cheng, H. M. The reduction of graphene oxide. Carbon 2012, 50, 3210-3228.

29. Thomson, T. L.; Yates, Jr, J. T. TiO -based Photocatalysis: Surface Defects, Oxygen and Charge Transfer, Top. Catal. 2005, 35, 197.

30. Schaub, R.; Thostrup, P.; Lopez, N.; Laegsgaard, E.; Stensgaard, I.; Norskov, J. K.; Besenbacher, F. Oxygen Vacancies as Active Sites for Water Dissociation on Rutile $\mathrm{TiO}_{2}$ (110). Phys. Rev. Lett. 2001, 87, 266104.

31. Lu, W.; Gao, S.; Wang, J. One-pot synthesis of Ag/ZnO self-sssembled 3D hollow microspheres with enhanced photocatalytic performance. J. Phys. Chem. C, 2008, 112, 16792-16800.

32. Zubkov, T.; Stahl, D.; Thompson, T. L.; Panayotov, D.; Diwald, O.; Yates, J. T. Ultraviolet light-induced hydrophilicity effect on $\mathrm{TiO}_{2}(110)(1 \mathrm{x} 1)$. Dominant role of the photooxidation of adsorbed hydrocarbons causing wetting by water droplets. J. Phys. Chem. B 2005, 109, 15454-15462.

33. György, E.; Pérez del Pino, Á.; Logofatu, C.; Cazan, C.; Duta, A. Simultaneous laserinduced reduction and nitrogen doping of graphene oxide in titanium oxide/graphene oxide composites. J. Am. Ceram. Soc., 2014, 97, 2718-2724.

34. Xu, Z.; Ao, Z.; Chu, D.; Younis, A.; Li, C. M.; Li, S. Reversible hydrophobic to hydrophilic transtion in graphene via water splitting induced by UV irradiation. Scientific Reports, 2014, 4, 6450(1-9).

35. Zhang, X.; Wan, S.; Pu, J.; Wang, L.; Liu, X. Highly hydrophobic and adhesive performance of graphene films. J. Mater. Chem. 2011, 21, 12251-12258.

36. Shibuya, M.; Miyauchi, M. Site-Selective Deposition of Metal Nanoparticles on Aligned $\mathrm{WO}_{3}$ Nanotrees for Super-Hydrophilic Thin Films. Adv. Mater. 2009, 21, 1373-1376.

37. Muhich, C. L.; Zhou, Y.; Holder, A. M.; Weimer, A. W.; Musgrave, C. B. Effect of surface deposited Pt on the photoactivity of $\mathrm{TiO}_{2}$. J. Phys. Chem. C, 2012, 116, 10138-10149.

38. Yildiz, A.; Lisesivdin, S. B.; Kasap, M.; Mardare, D. Electrical properties of $\mathrm{TiO}_{2}$ thin films, J. Non-Cryst. Solids, 2008, 354, 4994-4947.

39. Li, B.; Zhang, X.; Li, X.; Wang, L.; Han, R.; Liu, B.; Zheng, W.; Li, X.; Liu, Y. Photoassisted preparation and patterning of large-area reduced graphene oxide- $\mathrm{TiO}_{2}$ conductive thin film. Chem. Commun. 2010, 46, 3499-3501. 
40. Gomez-Navarro, C.; Weitz, R. T.; Bittner, A. M.; Scolari, M.; Mews, A.; Burghard, M.; Kern, K. Electronic Transport Properties of Individual Chemically Reduced Graphene Oxide Sheets. Nano Lett. 2007, 7, 3499-3503.

41. Sahito, I. A.; Sun, K. C.; Arbab, A. A.; Qadir, M. B.; Jeong, S. H. Integrating high electrical conductivity and photocatalytic activity in cotton fabric by cationizing for enriched coating of negatively charged graphene oxide. Carbohydrate Polymers, 2015, 130, 299-306.

42. Kang, J. H.; Kim, T.; Choi, J.; Park, J.; Kim, Y. S.; Chang, M. S.; Jung, H.; Park, K. T.; Yang, S. J.; Park, C. R. Hidden Second Oxidation Step of Hummers Method. Chem. Mater. 2016, DOI: 10.1021/acs.chemmater.5b03700. 